\title{
Breadth of Vocabulary, and Frequency and Recycling of Vocabulary Items in Primary Schools' English Course Books
}

\author{
Thomas Zapounidis \\ Aristotle University of Thessaloniki \\ zapakias@yahoo.com
}

\section{Abstract}

This paper examines vocabulary issues with regard to the English course books taught in Greek primary state-schools by examining the older and recently introduced new English course books. Quantitative and qualitative analyses at a variety of levels (unit, course book, series) unfold concerning: (a) the total size of vocabulary breadth, (b) the frequencies of vocabulary items compared to those in a native corpus, and (c) the actual recycling of vocabulary items in the two series.

\section{Introduction}

The present paper is part of an MA research aiming to enrich the literature in vocabulary issues by investigating (a) the size of the vocabulary, (b) the frequency of items, and (c) the recycling of vocabulary items in both the older and new English course books (CBs) taught in Greek State primary schools. The corpus-based analyses of these CBs at a variety of levels (unit, book, and series) provide valuable data concerning the tokens and types of the older and new CBs (henceforth OCBs and NCBs) with regard to the concepts of size, frequency and recycling. High frequency vocabulary, lack of recycling and the need to match patterns with native corpora are but a few reasons that explain why the findings of this research are expected to be of great value not solely to practicing teachers, but for course book writers as well.

\section{Theoretical Backgrounds}

When dealing with measures of vocabulary of a language a number of terms such as breadth, frequency and recycling become prominent. The establishment of such terms means they will also be used in the research on making the

\section{(cc) BY-NC-ND}


comparisons between the CBs, but their use will differ slightly, as will be explained later.

\subsection{Breadth of Vocabulary}

Breadth of vocabulary is an important dimension of vocabulary description and refers to "the number of words one has at least superficial knowledge of (i.e. one's vocabulary size)" (Matsuoka and Hirsh, 2010: 58).

Although possessing the full breadth of vocabulary of a language is deemed unattainable ${ }^{1}$, size of vocabulary is still considered significant in comprehending any language. Increased vocabulary proficiency has shown significant correlation with L2 reading proficiency (Coady, Magoto, Hubbard, Graney and Mokhtari, 1993; Laufer, 1992; Qian, 1999) as well as with writing ability (Astica, 1993; Laufer and Nation, 1995). Further research has indicated that for unassisted reading, $95 \%$ of all the running words should be known to the reader (Laufer, 1992) and this necessitates a minimum knowledge of about 3,000 word families ${ }^{2}$. However, a more fluent reading and guessing of unknown words, necessitates a number of 5,000 word families for $98 \%$ coverage of texts (Coady, Magoto, Hubbard, Graney and Mokhtari, 1993; Hirsh and Nation, 1992; Laufer, 1997).

Still, the acquisition of 3,000 or 5,000 word families in an EFL instructed context is not an easy task for young learners. Cameron (2001) considers a realistic goal for vocabulary learning about 500 words per year, while Milton and Meara (1998) mention that only 4 words for each hour of tuition might be learned. Therefore, the CBs should be looked at with the purpose of seeing how successfully they increase learner vocabulary breadth.

\subsection{Frequency of Vocabulary Items}

Increasing the size of an individual's lexical items in any language necessitates the selection of the optimum vocabulary to be taught and the best way to present it. A useful criterion, among others, for choosing what vocabulary to teach is the frequency with which any particular vocabulary item appears in the language.

1 According to Nation and Waring (1997), the English language is said to contain about 54,000 word families which is a huge amount to master, even for native speakers (Schmitt, 2000).

2 A word family consists of a base form and all its derived and inflected forms. 
According to Nation (2001a), there are four categories of vocabulary items that can be distinguished when frequency is considered: high frequency items, low frequency items, academic items and technical items. The high frequency items seem to constitute the most significant target group of words. They refer to the 2,000 most frequent words of any language and are deemed important as they constitute a significant percentage of words (80\%) in any text (Schmitt and McCarthy, 1997: 9-10). The need to acquire the most frequent vocabulary items is further corroborated in language teaching contexts. According to Nation (2001a: 167) "High frequency words deserve direct teaching and classroom time".

Despite the significance of high frequency words, Milton and Vassiliu (2000) found low level EFL CBs then in use in Greece to contain a considerable amount of infrequent vocabulary items which seems inappropriate for this level considering that a great percentage of infrequent vocabulary is a characteristic of technical texts (Milton and Hales, 1996:72). Therefore an examination of $\mathrm{CBs}$ should investigate how the high frequency items of the language are incorporated into the course books to help learners gain valuable items.

\subsection{Recycling of Vocabulary Items}

Muchasanindividual's mental lexicon(Aitchison, 1998:97) can accommodate a vast amount of information, there are times when information cannot be retrieved. The decay theory states that stored information when not used in a short time is prone to being forgotten (Gairns and Redman, 1986: 89) and the cue-dependent forgetting states that information persists in the memory but cannot be retrieved (ibid). Therefore, lexical acquisition not only "requires multiple exposures to a word" (Schmitt, 2000: 137), but also, as there is only a 5\%-14\% chance of retaining a word from one exposure (Nagy, 1997: 74), "recycling previously met words in varied contexts and activities is essential to keep learnt words active" (Cameron, 2001: 95). Although the exact number of repetitions that is required for establishing learning varies from study to study, it is certain that one or two exposures to the word do not suffice for its acquisition and so a systematic recycling is required in teaching materials.

To this end, foreign language CBs should be examined for the extent of vocabulary recycling they provide. López-Jiménez (2009), for instance, identified in 12 textbooks for teaching English in Spain that words were not recycled much. Furthermore "in some courses, half of the different words occur only once and most of the words occur less than five times" (Nation, 1990:44). Finally, special attention should also be paid to vocabulary that has been learned first in a course as this is the first to be forgotten (Laufer, Meara, and Nation, 2005:3; 
Nation, 1990: 45). Therefore CBs should be examined to reveal the patterns of recycling and how this helps learning of vocabulary.

\subsection{ELT Teaching in Greek State Primary Schools}

The teaching of foreign languages was introduced in Greek primary schools in 1987, and in 1991 it became compulsory for the last three grades ${ }^{3}$ (ages nine to twelve) of the six and was taught for three hours per week at each grade ${ }^{4}$. A specified course book (Funway 1, 2, 3 respectively) was taught for each of the three grades. In 2003, the instruction of English in Greek State schools was introduced at the third grade of primary school, and the selection of a CB for the $3^{\text {rd }}$ grade is done by the teachers; they were required to select from a list of approved CBs that is prepared each year by the Ministry of Education Lifelong learning and Religious Affairs. The CBs for the next three grades $\left(4^{\text {th }}, 5^{\text {th }}\right.$, and $\left.6^{\text {th }}\right)$ remained the Funway series CBs until the school year 2009-2010 when they were replaced by the new series of English CBs.

A revised unified curriculum was introduced through the Government Gazette No 304/13-3-2003 that enriched the development of literacy and communicative competence with awareness of multilingual and multicultural aspects of language learning; this new trend is evident in a number of features of the NCBS that include: Cross-curricular/crosscultural content, self-assessment and portfolio sections, strategy sections, grammar tables, pedagogically informed guidelines for teachers (Bratsoli and Diamandidou, 2009:7-16).

In addition to the above changes, very recent governmental decisions enacted the increase by one hour (from three to four hours a week) of the English instruction from the $3^{\text {rd }}$ to the $6^{\text {th }}$ grade, and the introduction of English language teaching in the first and second grades of Primary school (about 7-8 year old learners) for two hours per week. These changes were introduced in $800^{5}$ pilot schools from the school year 2010-2011in an attempt to: (a) promote early language learning and (b) counterbalance the distinct phenomenon of the "thriving private sector of foreign language institutes" (Mattheoudakis and Alexiou, 2009:230) and of private tuition.

3 Grade is the term used instead of level.

4 There are two extra hours for each grade of the all day school (this type of school ends at 16.15 instead of 13.15) but during these hours consolidation of knowledge is aimed for and not presentation of new language.

5 The number of this type of schools was increased with 161 more schools in the next school year (2011-2012). 


\section{Methodology}

Preparatory to any elaboration on the corpus design, an explanation of the slight different use of the terms, described in the theoretical backgrounds section, is needed. Given that there is a specific breadth of vocabulary knowledge required to 'know' a language, course books have to approach the presentation of a specific amount of vocabulary items for learners to become equipped. In this light, the term breadth, in this research, refers to the total amount of types/ tokens in the CBs whereas the term frequency is to see whether high-frequency tokens in the language are the same as those that are given such a ranking in the English language. Finally, the term recycling in the research will examine which tokens and types are recycled as the books proceed.

\subsection{Corpus Design}

Taking into consideration that pedagogic corpora include all the language learners are exposed to in educational contexts, attempts were made to include in the corpus for this research all the material that has been produced by the Ministry of Lifelong Education and Religious Affairs. Therefore, student books, activity books (also called workbooks) and the listening materials (411 minutes, in total, from cassettes and $(D)$ ) of each grade of the primary school were included in this research project.

The researcher typed about $80 \%$ of the above mentioned material (12 primary school books) down to its last detail (from the front page to appendices and back cover, including all details, such as names of roads in maps); the remaining $20 \%$ was copied and includes pages of the NCBs. Typing all this material was a lengthy and time consuming process that took several months to complete. The corpus eventually totaled about 1,800 pages of all the books. Typing, instead of scanning, all this material was considered necessary as map details and picture information (e.g. T-shirt words, titles of books) would have been missed had the scanning (in the case of the OCBs) and copy-paste methods been used.

The material was categorized into many sub-corpora in order to facilitate the various analyses. In this light, there were (a) two 'comprehensive' corpora; one comprising the student books, workbooks and listening material of the older CBs (Funway 1, 2, 3) and the second one comprising the student books, workbooks and listening material of the NCBs (b) six 'basic' subcorpora that include the full material (student book, workbook and listening material) of each grade. Therefore, there is one for Funway 1, one for Funway 2, one for Funway 3, and respectively one for each CB of the new set, and (c) about 180 'unit' subcorpora that represent each one of the units of the student book, workbook and listening material of each CB of each series. 


\subsection{The Tools}

Two main tools were used in the present project. The first is the FREQUENCY program (Heatley, Nation, and Coxhead, 2002) which can produce frequency lists of all the words in texts in either alphabetical or frequency order with information about the rank order of words, raw frequency and cumulative percentage frequency. The second is the ANTWORDPROFILER software (previously named AntVocabCheck), developed by Professor Laurence Anthony in the Center for English Language Education in Science and Engineering at Waseda University, Japan. This software is based on Paul Nation's RANGE program (it even uses three of Paul Nation's baseword lists as its default lists) but its interface is more functional and it further includes Unicode characters that enable it to recognize other languages as well. This word profiling tool was used in comparing the texts from the same or different CBs.

\subsection{Framework of Analysis}

The tools and the categorization of the corpora into a number of sub-corpora enabled multileveled analyses of all materials. As Figure 1 indicates, all data for each series were analyzed vertically, horizontally and diagonally. This three directional framework mirrors analyses at three different levels: at unit level (vertical), at CB level (horizontal), and at series level (diagonal). In particular, at the vertical level the units within each $\mathrm{CB}^{6}$ are compared in terms of their contribution to: (a) size, (b) frequency and (c) recycling of vocabulary. At the horizontal level a comparison of the first, second and third book for each set of CBs (old and new ones) is presented. Each CB is analyzed separately in terms of: (a) breadth of vocabulary (size) (b) frequency and (c) recycling of vocabulary. The diagonal level considers all three CBs of each set together and examines the size, frequency and recycling of vocabulary items in the whole series.

These analyses aimed to produce both quantitative and qualitative data. The former refer to the total number of items in measuring size, frequency and recycling in the CBs whereas the latter refers to the identification of the items. The identification of the type of the items of the CBs was achieved by classifying items into five distinct categories: (a) Core, (b) Names, (c) Places, (d) Foreign (lexical items), and (e) Greek (lexical items). The Core category included the main body of lexical items, that is English common (not proper) words. The Names

6 The term CB refers to all the material (student book, workbook and transcribed audio cassette or $(D)$ of that $C B$. 
category included proper names (names, surnames, brands, email addresses and so on). The Places ${ }^{7}$ category included items referring to places such as streets, countries, continents and nationalities. The Foreign category included items that belong to any other language other than the English and Greek ones (e.g. bonjour, buenos). Finally, the Greek category included Greek vocabulary items. The above categorization intends to examine the identity of tokens so as to examine in more detail the differences of the total number of vocabulary between the CBs.

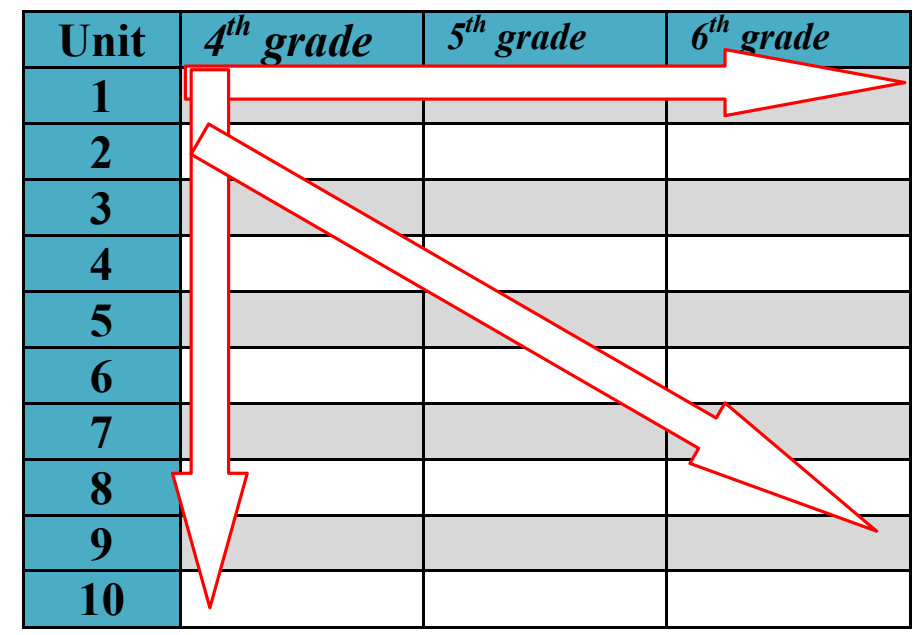

Figure 1. Three directional framework of analysis in the Funway series.

\section{Results and Discussion}

Taking into consideration the extensive amount of data of this research in terms of tables and appendices (more than 40 different tables and 90 pages of data in appendices) and the limited scope of this paper, only a number of key findings is presented.

7 It was considered proper to break proper names into two categories (Names and Places) so as to examine the extent to which use of maps and geographical descriptions or names, surnames contribute to the total number of types and tokens. 


\subsection{Size of the Total Number of Vocabulary Items}

The vertical analysis aimed to examine the vocabulary size of each unit within all CBs. The vocabulary size of each unit in terms of the total number of tokens and types follows a gradual increase in the number of tokens in both the old and new CBs with a significantly higher average in the new material. This seems partly natural given the maturity of learners with each new grade and their ability to cope with more material. Types follow a similarly increasing pattern with the exception of the last two NCBs (5th and 6th grades); in these CBs units have about the same average $(1,195$ and 1,168).

The results of the qualitative analyses of the material in terms of tokens and types indicate that the majority of the words are found in the 'Core' category. Differences between the old and new CBs exist in the slightly increased number of 'Names' and 'Places' (5th grade) in the new material. However, the most important difference between the two sets of CBs is the greater percentage of Greek lexical items, both tokens and types, found in the NCBs. An example from the qualitative analysis of the $4^{\text {th }}$ grade's old and new material is provided in Table 1. Although the presence of Greek lexical items in the units of the NCBs is mainly located in the self-assessment sections and the appendices, they may significantly reduce learners' exposure to the English language.

The horizontal analysis compared the units of the first $C B$ with the equivalent units of the next two CBs with the aim of examining the pattern of tokens/ types across the CBs of the same set. Results indicated that the older CBs demonstrated a more balanced distribution of vocabulary both in terms of tokens and types when compared to the NCBs, to the 5th grade NCB in particular.

Finally, the aim of the diagonal analysis was to measure the total size of vocabulary that learners are exposed to through the use of the CBs over a period of three years ( $4^{\text {th }}$ to $6^{\text {th }}$ grade). The results of this kind of analysis are presented in Table 2 . As can be seen the new material includes more than double types and tokens compared to the older material. This may partly be attributed to the increased size of the NCBs in terms of pages (2 extra pages for each unit compared to the Funway series). Still, the size of the NCBs may be considered great considering the 500 words a year that Cameron (2001) mentioned.

Further qualitative analysis of the tokens and types of Table 2 produced the results of Table 3 . In this table the most notable information regarding types of all the old and new CBs are: (a) a quarter of the types (26.43\%) in the NCBs are Greek compared to the corresponding $12.84 \%$ percentage in the old CBs, and (b) a considerable decrease of percentage of the types in the 'Core' category in the NCBs; about half of them (56.6\%) are included in this category whereas 
Table 1.

Qualitative analysis of tokens in the 4th grade's old and new material.

\begin{tabular}{|c|c|c|c|c|c|}
\hline \multicolumn{6}{|c|}{ Funway 1 tokens } \\
\hline UNIT & CORE & NAMES & PLACE & FOREIGN & GREEK \\
\hline Preunit & $46.75 \%$ & $2.54 \%$ & $1.03 \%$ & $0.16 \%$ & $49.52 \%$ \\
\hline 1 & $90.32 \%$ & 9,50 & 0.18 & 0 & 0 \\
\hline 2 & 91.83 & 8.17 & 0 & 0 & 0 \\
\hline 3 & 97.72 & 2.28 & 0 & 0 & 0 \\
\hline 4 & 97.25 & 2.75 & 0 & 0 & 0 \\
\hline 5 & 97.88 & 1.83 & 0.29 & 0 & 0 \\
\hline 6 & 96.96 & 1.83 & 0.74 & 0.47 & 0 \\
\hline 7 & 98.39 & 1.57 & 0.04 & 0 & 0 \\
\hline 8 & 97.42 & 2.51 & 0.07 & 0 & 0 \\
\hline 9 & 98.48 & 1.37 & 0.15 & 0 & 0 \\
\hline 10 & 89.44 & 2.82 & 6.14 & 0.08 & 1.52 \\
\hline Appendix & $90.32 \%$ & 9,50 & 0.18 & 0 & 0 \\
\hline Average & 91.06 & 3.88 & 0.73 & 0.05 & 4.25 \\
\hline \multicolumn{6}{|c|}{$4^{\text {th }}$ grade NCB tokens } \\
\hline UNIT & CORE & NAMES & PLACE & FOREIGN & GREEK \\
\hline 1 & 80.95 & 2.73 & 1.34 & 0 & 14.98 \\
\hline 2 & 84.85 & 3.10 & 0.70 & 0 & 11.35 \\
\hline 3 & 78.08 & 2.88 & 5.94 & 0 & 13.10 \\
\hline 4 & 90.38 & 2.39 & 0.84 & 0 & 6.39 \\
\hline 5 & 90.05 & 2.18 & 1.35 & 0 & 6.42 \\
\hline 6 & 84.80 & 2.94 & 2.17 & 0.15 & 9.94 \\
\hline 7 & 89.25 & 4.17 & 0.38 & 0.06 & 6.14 \\
\hline 8 & 90.42 & 1.49 & 0.46 & 0.03 & 7.60 \\
\hline 9 & 96.82 & 1.20 & 0.44 & 0.03 & 1.51 \\
\hline 10 & 91.38 & 1.98 & 1.36 & 0.02 & 5.26 \\
\hline Appendix & 56.29 & 1.56 & 1.34 & 0.04 & 40.77 \\
\hline Average & 84.84 & 2.42 & 1.48 & 0.03 & 11.22 \\
\hline
\end{tabular}

Table 2.

Total number of vocabulary for the two series of CBs.

\begin{tabular}{|l|l|l|}
\hline & Funway CBs & NCBs \\
\hline Tokens & $\mathbf{7 4 , 5 9 1}$ & $\mathbf{1 7 8 , 1 4 0}$ \\
\hline Types & $\mathbf{5 , 4 0 6}$ & $\mathbf{1 1 , 2 0 4}$ \\
\hline
\end{tabular}


the corresponding percentage in the old CBs is $73.99 \%$. As far as tokens are concerned, no important differences seem to exist.

Table 3.

Qualitative analysis of vocabulary size (tokens/types) for both series.

\begin{tabular}{|c|c|c|c|c|}
\hline \multicolumn{5}{|l|}{ Funway } \\
\hline BASEWORD & TOKENS & TOKENS\% & TYPES & TYPES\% \\
\hline Core & 68,751 & 92.17 & 4,000 & 73.99 \\
\hline Names & 1,954 & 2.62 & 389 & 7.20 \\
\hline Places & 1,046 & 1.40 & 271 & 5.01 \\
\hline Foreign & 74 & 0.10 & 52 & 0.96 \\
\hline Greek & 2,766 & 3.71 & 694 & 12.84 \\
\hline Total & 74,591 & 100 & 5,406 & 100 \\
\hline \multicolumn{5}{|l|}{ NCBs } \\
\hline BASEWORD & TOKENS & TOKENS\% & TYPES & TYPES\% \\
\hline Core & 150,753 & 84.62 & 6,348 & 56.66 \\
\hline Names & 11,216 & 6.30 & 844 & 7.53 \\
\hline Places & 3,719 & 2.09 & 941 & 8.40 \\
\hline Foreign & 317 & 0.18 & 110 & 0.98 \\
\hline Greek & 12,135 & 6.81 & 2,961 & 26.43 \\
\hline Total & 178,140 & 100 & 11,204 & 100 \\
\hline
\end{tabular}

\subsection{Frequency of Vocabulary}

From a quantitative point of view, analysis at the unit level of each CB involved identifying the most frequent items of each unit. Examination of the lists indicated a similar pattern for most of the units of almost all CBs; function words such as the, and in rank high in all of the units which is considered natural given that function words rank high in almost all frequency lists including those of the British National Corpus which may be considered as representative of the English language. As far as content words are concerned, 'unit' and 'lesson' rank high (20th and above) in most of the units; this is attributed to the display of the words on each page of the CBs. Furthermore, the titles of each unit on every page account for the varied frequency of content words such as 'school', 'student', 'favourite', 'education', 'treasure' and so on, in a number of units of both the old and new CBs.

The qualitative analysis of the frequency of vocabulary items involved the comparison of all the items in each unit of each CB with the 14,000 most frequent 
words of the English language according to the British National Corpus in order to examine whether high frequency tokens of the English language are equally frequent in the language of the CBs. The results indicated that at unit level the $N C B s$, compared to the Funway ones, contain more items that are not included in the 16 BNC lists. This seems to imply that the language of the Funway series is more representative of the English language as it includes more items that are among the most frequent words of the English language (BNC lists).

The analysis at the $C B$ level involved the comparison of the 100 most frequent words in each CB. Comparison of the 100 most frequent words among the three CBs of both the old and the new series indicate, as in the case of the unit analysis, that there are many similarities regarding function words: articles such as the rank first in all books while $a$ ranks second or third.

Analysis at the series level involved the comparison of two large frequency lists; the first one included the 1,000 most frequent items of all the three CBs of the Funway series whereas the other included the 1,000 most frequent words in all three NCBs. The comparison of these two lists indicated that there are 672 $(67.2 \%)$ common words in these two lists. A more qualitative analyses of these 672 common items included their comparison against the BNC lists. Results indicated that these common words of the two 1,000 most frequent word lists belong indeed to the most frequent words of the English language; more than $94 \%$ of the 672 words are contained in the first two lists (the 2,000 most frequent words of the English language).

Comparison of all the items of the CBS with the 16 BNC lists indicated that whereas more than $80 \%$ of the tokens included in both the old and new CBs are included in the 3,000 most frequent words of the English language according to the BNC frequency lists, the same does not apply to the case of types; only half of the types (54.85\%) of the Funway series and less than half $(42.36 \%)$ of the types of the new series are included in the 3,000 most frequent words of English. This last discrepancy between the tokens and types is largely explained by the 'Not in the lists' category which contains words that were not found in any of the 16 BNC lists; $22.49 \%$ of the types in the Funway series and $34.98 \%$ of the types in the NCBs are not present in the 16 BNC lists and further qualitative analysis indicate that this is largely due to the increased presence of the Greek items.

\subsection{Recycling of Vocabulary in the CBs}

The horizontal mode of analysis focused on identifying repetition of English vocabulary items of the first $C B$ in the second, of the second one in the third one, and of the first one in the second and third ones together. This form of comparison indicated, on the one hand, the degree of repetition within the 
same type of CBs (old or new) and, on the other hand, the degree of expanded repetition (cf. Baddeley, 1990, cited in Schmitt, 2000) one year after or two years after the first CB had been taught. The results from this analysis showed that about two thirds of the types of the Funway series are repeated (at least once) in each successive CB (63.97\% and 67.51\%). Funway 2 and 3 repeat $78.62 \%$ of the items presented in Funway 1. With reference to the NCBs, $78.09 \%$ of 4 th grade NCB vocabulary items are repeated in the 5 th and 6 th grade NCBs.

The above data were supplemented with the calculation of the precise number of repetition for each item. In the results that follow only items with a number of 5 or more occurrences were included. With respect to the Funway CBs only 433 out of the 847 repeated items between Funway 1 and Funway 2 and 656 out of the 1,525 repeated items between Funway 2 and Funway 3, occur five or more times. Out of the 1,041 types found in Funway 2 and Funway 3 only 473 (45.43\%) were found to be recycled five or more times.

As far as the number of repetitions in the NCBs is concerned, 847 types $(56.43 \%)$ of 4 th grade NCB are repeated five or more times in the 5 th grade NCB; the respective number of types of the 5 th grade $N C B$ repeated in the 6 th grade NCB is 1,296 (45.42\%, Table 4.19). This shows that as in the case of the old material only about half of the items are recycled at least five times. Even when viewed collectively, 5th and 6th grade NCBs fail to recycle $4^{\text {th }}$ grade's types to a great extent; of the 1,718 types found in the 5th and 6th grade NCBs only 916 $(53.31 \%)$ are repeated at least five times.

Further analysis examined the recycling of the vocabulary items in the same unit of student book and workbook. In other words, we examined whether each unit in a workbook recycles vocabulary items of the corresponding unit of the student book. Results indicated that types found in the student book units of the NCBs are slightly better recycled in the corresponding units of the workbooks; the averages of $79.13 \%, 72.85 \%$, and $75.16 \%$ of the Funway CBs (Table 4.27 ) are slightly lower than the corresponding averages of $85.36 \%, 77.23 \%$, and $78.60 \%$ of the NCBs (Table 4.28).

\section{Concluding Remarks}

The primary aim of this study was to conduct a corpus-based comparative study of the old and new English CBs in Greek State primary schools; in particular, the study investigated the breadth, frequency, and recycling of vocabulary items of the CBs.

The major finding in terms of size was that the NCBs include more than double tokens and types than those found in the Funway series. As far as frequency of items is concerned, items of the old CBs proved to be those that are slightly more frequent in the English language according to the BNC lists. Regarding 
the recycling of vocabulary items, both the old CBs and the NCBs only partially recycle their lexical items. A finding influencing all the above variables was found to be the increased percentage of Greek items (mainly in the appendix sections) in the NCBs.

This study attempted to enrich research regarding vocabulary issues of the English CBs taught in Greek State primary schools. In particular, the findings regarding the breadth, frequency and recycling of lexical items in these CBs are expected to be useful to teachers and course designers.

Primary school English language teachers have to take into consideration the increased vocabulary size of the NCBs and focus on the high frequency items of each unit or CB by teaching it explicitly (cf. Nation, 2001b) in an attempt to reduce significant lexical burden created by the increased size of vocabulary of the NCBs. The identification of the high frequency items should also be followed by a recycling of these items given their increased frequency in the English language. In turn, course designers are expected to take into consideration the high frequency vocabulary and the need to recycle it. More frequent vocabulary items of the English language, preferably those belonging to the first two BNC lists (2,000 most frequent items), should be included in all English CBs. Also, the direct teaching of the, which is among the most frequent items in almost all frequency lists, seems to have passed unnoticed by all stakeholders (Pedagogic Institute, state consultants, course designers, and some teachers) of the educational context who should perhaps include the in the appropriate grammar sections (articles) of the CBs. Finally, the thematic content of the units should be organized in such a way that it will allow adequate recycling of all the previously presented vocabulary.

The findings of the present study have shed light to a number of differences in terms of breadth, frequency, and recycling of vocabulary items between the older and new CBs. Most importantly, the increased number of tokens in the $N C B s$, the insufficient recycling of vocabulary in the series and the presence of some Greek vocabulary in some of the NCBs should raise awareness of all stakeholders in the educational context and initiate efforts of improving CBs taught at schools so that the level of the English language learning and teaching is of the best quality. The NCBs may have included cross-curricular/ cross-cultural content, self-assessment and portfolio sections, strategy sections, grammar tables, pedagogically informed guidelines for teachers but it is the writer's opinion that more can be done in terms of vocabulary. For vocabulary instruction is too serious a matter to be dealt with unsystematically. 


\section{References}

Aitchison, J. 1998. Words in the mind: An introduction to the mental lexicon. Oxford: Blackwell.

Astika, G.G. 1993. Analytical assessment of foreign students' writing. RELC Journal, 24: 61-72.

Bratsoli, A. and A. Diamantidou. 2009. English 4th Grade: Teacher's book. Athens: School Book Publishing Organization.

Cameron, L. 2001. Teaching languages to young learners. Cambridge: Cambridge University Press.

Coady, J., J. Magoto, P. Hubbard, J. Graney and K. Mokhtari. 1993. High frequency vocabulary and reading proficiency in ESL readers. In T. Huckin, M. Haynes and J. Coady (eds.), Second language reading and vocabulary learning. New Jersey: Ablex, 217-228.

Gairns, R. and S. Redman. 1986. Working with words: A guide to teaching and learning vocabulary. Cambridge: Cambridge University Press.

Heatley, A., P. Nation and A. Coxhead. 2002. RANGE and FREQUENCY programs. Retrieved 20 May 2009 from http://www.vuw.ac.nz/lals/staff/Paul_Nation

Hirsh, D. and P. Nation. 1992. What vocabulary size is needed to read unsimplified texts for pleasure? Reading in a Foreign Language 8,(2): 689-696.

Laufer, B. 1992. How much lexis is necessary for reading comprehension? In H. Bejoint and P. Arnaud (eds.), Vocabulary and Applied Linguistics. London: Macmillan, 126-132. 
Laufer, B. 1997. The lexical plight in second language reading: Words you don't know, words you think you know, and words you can't guess. In J. Coady and T. Huckin (eds.), Second language vocabulary acquisition: A rationale for pedagogy. Cambridge: Cambridge University Press, 20-34.

Laufer, B., P. Meara and P. Nation. 2005. Ten best ideas for teaching vocabulary. The Language Teacher, 29 (7): 3-6.

Laufer, B. and P. Nation. 1995. Vocabulary size and use: Lexical richness in L2 written production. Applied Linguistics, 16 (3): 10-14.

López-Jiménez, M.D. 2009. The treatment of vocabulary in EFL textbooks. ELIA, 9: 59-81.

Matsuoka, W. and D. Hirsh. 2010. Vocabulary learning through reading: Does an ELT course book provide good opportunities? Reading in a Foreign Language, 22 (1): 56-70.

Mattheoudakis, M. and T. Alexiou. 2009. Early foreign language instruction in Greece: Socioeconomic factors and their effect on young learners' language development. In M. Nikolov (ed.), The age factor and early language learning. New York: Mouton de Gruyter, 227-252.

Milton, J. and T. Hales. 1996. Applying a lexical profiling system to technical English. In A. Ryan and A. Wray (eds.), Evolving models of language. Clevedon: Multilingual Matters, 72-83.

Milton, J. and P. Meara. 1998. Are the British really bad at learning foreign languages? Language Learning Journal, 18: 68-76.

Milton, J. and P. Vassiliu. 2000. Frequency and the lexis of low level EFL texts. In K. Nicolaidis, and M. Mattheoudakis, (eds.) Proceedings of the 13th international symposium on theoretical and applied linguistics, Aristotle University of Thessaloniki, 444-455.

Nagy, W.E. 1997. On the role of context in first-and-second- language vocabulary learning. . In N. Schmitt and M. McCarthy (eds.), Vocabulary: Description, acquisition and pedagogy. Cambridge: Cambridge University Press, 64-83.

Nation, P. 1990. Teaching and learning vocabulary. Massachucetts: Heinle \& Heinle Publishers. 
Nation, P. 2001a. Learning vocabulary in another language. Cambridge: Cambridge University Press.

Nation, P. 2001b. How many high frequency words are there in English? In M. Gill, A. Johnson, L. Koski, R. Sell, and B. Warvik (eds.), Language, learning literature: Studies presented to Hakan Ringbom. Turku: English Department Publications, 167-181.

Qian, D. 1999. Assessing the roles of depth and breadth of vocabulary knowledge in reading comprehension. The Canadian Modern Language Review, 56: 283-307.

Schmitt, N. 2000. Vocabulary in language teaching. Cambridge: Cambridge University Press.

Schmitt, N. and M. McCarthy. 1997. Vocabulary: Description, acquisition, and pedagogy. Cambridge: Cambridge University Press. 